\title{
Perempuan dan Hak Waris: Kajian Teologis Bilangan 27:1-11*
}

\author{
Women and Inheritance Rights: A Theological Studies of Numbers 27:1-11
}

\author{
Feniati Zebua ${ }^{\boxplus}$, Juliman Harefa ${ }^{1}$ \\ 1Sekolah Teologi Teologi Banua Niha Keriso Protestan Sundermann
}

\section{ARTICLE INFO}

Submitted: September 7, 2021

Review: September 18, 2021

Accepted: December 30, 2021

Published: December 31, 2021

\section{KEYWORDS}

inheritance rights, Numbers 27:1-27,

property, women, Zelophehad

\section{CORRESPONDENCE}

Phone:

E-mail: feniatizebua96@gmail.com

\begin{abstract}
A B S TRACT
This article discusses inheritance, property owned by the father, which will then be passed on to his children from generation to generation. The people of Nias adhere to a patriarchal culture in which men are dominant over women, both in society and in the family. This affects the distribution of inheritance. The Bible shows that the cultural system is also patriarchal but still provides opportunities for daughters to inherit, as in Numbers 27:1-11 about the story of Zelaphehad's daughters. Using qualitative methods, the research was conducted in Sifalago Gomo, District of Boronadu, South Nias. The research findings show that inheritance is also given to daughters in some research areas for particular reasons. In this case, the church plays a role in providing understanding to the community about inheritance through preaching God's word and participating in giving an understanding to the public about inheritance in ancient times different from today so that there are no differences between men and women because all humans are equal before God.
\end{abstract}

\begin{abstract}
A B S T R A K
Artikel ini membahas tentang warisan, yaitu harta yang dimiliki oleh ayah, yang kemudian akan diwariskan kepada anak-anaknya secara turun temurun. Masyarakat Nias menganut budaya patriarkat dimana anak laki-laki dominan terhadap anak perempuan, baik dalam masyarakat maupun dalam keluarga. Hal ini mempengaruhi pembagian harta warisan. Alkitab menunjukkan bahwa sistem budaya juga patriarkat tetapi masih memberikan kesempatan bagi anak perempuan untuk mewarisi, seperti dalam Bilangan 27:1-11 tentang kisah anak-anak Zelafehad. Dengan menggunakan metode kualitatif, penelitian ini dilakukan di Sifalago Gomo, Kecamatan Boronadu, Kabupaten Nias Selatan. Temuan penelitian menunjukkan bahwa warisan juga diberikan kepada anak perempuan di beberapa daerah penelitian karena alasan tertentu. Dalam hal ini gereja berperan memberikan pemahaman kepada masyarakat tentang warisan melalui pemberitaan firman Tuhan dan ikut memberikan pemahaman kepada masyarakat tentang warisan pada zaman dahulu berbeda dengan zaman sekarang sehingga tidak ada perbedaan antara laki-laki dan perempuan karena semua manusia adalah sama di hadapan Tuhan.
\end{abstract}

Kata kunci: Bilangan 27:1-27, hak waris, patriarkat, perempuan, Zelafehad

\section{PENDAHULUAN}

$\mathbf{H}$ ukum warisan merupakan suatu sistem hukum adat yang memuat garis keturunan dalam sistem asas-asas yakni hukum waris, harta warisan, pewaris serta tata cara warisan itu ketika dialihkan dari pewaris 
kepada yang mewarisinya. ${ }^{1}$ Harta warisan merupakan suatu sistem hukum adat berdasarkan budaya setempat dan hukum adat yang telah ada sejak dahulu kala dan telah menjadi kebiasaan-kebiasaan sampai sekarang.

Meskipun zaman telah berubah baik dalam pendidikan, budaya, politik dan sosial, namun dalam kenyataan hidup yang diterapkan dalam masyarakat Nias masih sangat kuat ikatannya dengan Patriarkat. Perempuan dianggap sebagai penguasa domestik (rumah) dan laki-laki adalah pemilik ruang publik. ${ }^{2}$

Demikian dengan pembagian harta warisan dalam suku Nias, warisan hanya diterima oleh anak laki-laki sebagai fangali börözisi (penerus keturunan) di dalam keluarga, karena suku Nias menganut sistem budaya patriarkat. Sistem budaya patriarkat merupakan sistem budaya yang keturunannya diambil dari anak laki-laki dan akan menjadi ahli waris dalam setiap keluarga ketika ayah telah meninggal, maka harta warisan akan diwarisi oleh anak laki-laki yang kemudian diteruskan kepada garis keturunan berikutnya. ${ }^{45}$

*Artikel ini merupakan intisari Skripsi Feniati Zebua, "Anak Perempuan Berhak Mendapatkan Harta Warisan: Kajian Teologis Terhadap Kitab Bilangan 27:111 dan Aplikasinya Terhadap Masyarakat Sifalago Gomo" (STT BNKP Sundermann, 2021).

1 Ellyne Dwi Poespasari, Pemahaman Seputar Hukum Waris Adat Di Indonesia, 1st ed. (Jakarta: Prenadamedia Group, 2018).

2 Yurulina Gulo, "Ketidakadilan Budaya Patriarkhi Terhadap Perempuan Di Nias," JUPIIS: Jurnal Pendidikan Ilmu-ilmu Sosial 11, no. 1 (June 18, 2019): 10, https://jurnal.unimed.ac.id/2012/index.php/jupiis/art icle/view/12305.

3 Memori Perdamaian Laoli, "Pelaksanaan Pembagian Warisan Pada Masyarakat Adat Nias (Studi Pada Masyarakat Adat Nias Di Kabupaten Nias Selatan)," Premise Law Jurnal (Universitas Sumatera Utara, 2016).

4 W. Gulo, ed., "Injil Dan Budaya Nias," in Seminar Lokakarya Perjumpaan Injil Dan Budaya Nias (Gunungsitoli: Panitia Semiloka, 2004).

5 Otoriteit Dachi and Vinna Isya Merti Manao, "Pelayanan Dan Kepemimpinan Pendeta Perempuan BNKP," SUNDERMANN: Jurnal Ilmiah Teologi, Pendidikan, Sains, Humaniora dan Kebudayaan 14, no. 1 (October 6, 2021): 29-38, https://jurnal.sttsundermann.ac.id/index.php/sunder mann/article/view/66.
Beberapa jenis harta yang dapat diwariskan dalam masyarakat Nias khususnya Gomo yaitu: ${ }^{6}$

- Tanah (Tanö) yang terdiri dari tanö laza (Sawah) dan tanö sabe'e (Tanah kering). Tanö kabu (tanah kebun) terdiri dari tanö naha nomo (tanah untuk tapak rumah) dan tanö mbenua (tanah yang digunakan untuk perkebunan), istilah dari semua jenis tanah ini disebut sebagai tanö mbenua.

- Rumah (Omo)

- Emas $\left(A n a^{\prime} a\right)$, emas terdiri dari Ana'a GamaGama Nina (Emas yang dipakai oleh ibu seperti kalung, cincin, gelang, anting-anting) dan Ana'a Nindradra (emas batangan seperti topi emas yang sering dipakai oleh perempuan pada acara pernikahan, juga emas batangan dalam bentuk besi ulir).

- Uang (Kefe)

- Kain atau Pakaian (Nukha)

- Tumbuhan di Kebun (Sinanö)

Hasil penelitian awal yang penulis lakukan di salah satu wilayah Kabupaten Nias Selatan yakni di Sifalago Gomo, penulis menemukan bahwa yang berhak mendapatkan warisan adalah anak laki-laki. Bahkan tatkala keluarga tidak memiliki keturunan laki-laki sekalipun, anak perempuan tidak diperkenankan mewarisi harta yang dimiliki orang tuanya, dan sebagai peganti ahli waris keluarga inti adalah saudara laki-laki dari ayah. Tradisi inilah yang akhirnya memicu persoalan baru di tengah-tengah keluarga besar, mulai dari ketidakharmonisan hubungan, pertengkaran mulut yang berujung pada pertengkaran fisik. Bahkan tak jarang ditemukan, masalah pembagian harta kekayaan ini berakhir dengan tindakan kriminal.

Di daerah Sifalago Gomo, pembagian harta warisan dilaksanakan pada saat melakukan acara adat fangotome'ö (memberi makan seseorang yang akan meninggal). ${ }^{7}$ Istilah fangotome'ö merupakan salah satu kegiatan atau hal yang dilakukan oleh setiap keluarga, ketika ayah atau ibu mengalami sakit parah, maka

6 Laoli, “Pelaksanaan Pembagian Warisan Pada Masyarakat Adat Nias (Studi Pada Masyarakat Adat Nias Di Kabupaten Nias Selatan)."

7 Tuhoni Telaumbanua, "Dunia Orang Mati Menurut Kepercayaan Masyarakat Nias," SUNDERMANN: Jurnal Ilmiah Teologi, Pendidikan, Sains, Humaniora dan Kebudayaan 14, no. 1 (June 26, 2021): 1-17, https://jurnal.sttsundermann.ac.id/index.php/sunder mann/article/view/49. 
dilaksanakan acara adat fangotome'ö tujuannya untuk melakukan fangandrö howuhowu (meminta berkat orang tua) dan pembagian harta warisan yang dimiliki oleh keluarga tersebut.

Pola pembagian harta warisan di daerah ini masih mengikuti hubungan kekerabatan melalui laki-laki dalam hal ini mengikuti garis keturunan ayah (patrilineal). Sehingga hanya anak laki-laki yang menjadi ahli waris, karena anak perempuan dianggap telah keluar dari kerabat bapaknya, jika ia telah kawin. ${ }^{8}$ Anak perempuan tidak mendapatkan pembagian harta warisan, karena anak perempuan dianggap akan mendapatkan warisan dari lakilaki yang akan menikahinya (suaminya). Demikian pula jika suatu keluarga memiliki anak laki-laki tunggal, maka anak tunggal tersebut yang berhak mendapatkan warisan, tetapi jika keluarga hanya memiliki anak perempuan tunggal, tetap saja anak perempuan tidak berhak mendapatkan warisan, dalam hal ini harta warisan dialihkan kepada anak lakilaki dari saudara ayah. Ini terjadi karena tradisi atau kebudayaan Nias yang menganut sistem kebudayaan patriarkat (bnd. Laia, 2005). ${ }^{9}$

Keputusan pembagian harta warisan sebagaimana dijelaskan di atas, seringkali menimbulkan persoalan baru ditengah-tengah keluarga besar. Pandangan bahwa perempuan tidak dapat mendapatkan harta warisan dalam keluarga adalah perlakuan diskrimiatif, dan ini menunjukkan semakin superiornya anak lakilaki di tengah-tengah masyarakat Nias secara khusus. Situasi ini semakin diperburuk oleh hubungan kekeluargaan yang tidak harmonis, dan tak jarang mengakibatkan pertengkaran fisik di antara anak laki-laki yang mewarisi harta warisan dari keluarga yang tidak memiliki anak laki-laki.

Penelitian ini bertujuan untuk memperhadapkan realita yang terjadi di masyarakat Sifalago Gomo dengan kisah anak Zelafehad. Secara teologis dalam teks Bilangan 27:1-11 "ketika anak-anak perempuan Zelafehad" datang untuk menemui Musa dan para imam dengan tujuan bagaimana supaya sebagian dari

8 Soerjono Soekanto, Hukum Adat Indonesia (Jakarta: Rajawali Pers, 2008), 240.

9 Fanotona Laia, "Kedudukan Anak Perempuan Dalam Hukum Waris Adat Pada Masyakakat Nias" (Universitas Sumatera Utara, 2005), http://repositori.usu.ac.id/handle/123456789/33440. harta warisan ayah Zelafehad dapat diberikan kepada anak perempuan tersebut. Dalam Kitab ini, terungkap bahwa permohonan dari anak perempuan dapat didengarkan oleh Musa yang kemudian disampaikan kepada Tuhan, sehingga di ayat 8 dikatakan "Dan kepada orang Israel engkau harus berkata: Apabila seseorang mati dengan tidak memiliki anak laki-laki maka haruslah kamu memindahkan hak atas milik pusakanya kepada anaknya yang perempuan." Hasil penelitian ini diharapkan dapat menjadi kontribusi praktis bagi kehidupan masyarakat Sifalago Gomo.

\section{METODE}

Penelitian ini dilaksanakan di Desa Sifalago Gomo Kecamatan Boronadu Kabupaten Nias Selatan. Dalam menemukan informasi terkait dengan topik penelitian, peneliti menggunakan metode kualitatif. Data dikumpulkandengan teknik wawancara semi terstruktur ${ }^{10}$ dan observasi. ${ }^{11}$ Pada bagian hasil dan pembahasan peneliti mendiskripsikan hasil studi eksegetis teks Kitab Bilangan 27:1-11 dalam menjawab masalah penelitian.

\section{HASIL DAN PEMBAHASAN}

Berdasarkan hasil wawancara dan observasi, penulis memeroleh data dan informasi sebagai berikut.

- Beberapa keluarga setuju bahwa anak perempuan dapat diberikan hak untuk mewarisi harta dalam keluarga. Namun dalam pemberian harta warisan misalnya tanah milik nenek moyang tidak dapat diberikan kepada keturunan perempuan karena merupakan warisan turun temurun dan hanya diperuntukan kepada anak lakilaki. Dalam hal ini, warisan kepada anak perempuan (tanah dan rumah) adalah harta milik ayahnya dan bukan dari orang tua yang dulu.

- Dalam Alkitab, anak perempuan bisa mendapatkan warisan dalam keluarga, tetapi masyarakat masih memahami bahwa hanya

10 H. Russell Bernard, Research Methods in Anthropology: Qualitative and Quantitative Approaches, 6th ed. (Maryland: Rowman \& Littlefield, 2017).

11 Brigitte Smit and Anthony J. Onwuegbuzie, "Observations in Qualitative Inquiry: When What You See Is Not What You See," International Journal of Qualitative Methods 17, no. 1 (December 2018). 
anak laki-laki yang bisa mendapatkannya, sedangkan anak perempuan tidak.

- Secara teologis, anak perempuan dapat mewarisi harta jika tidak memiliki saudara laki-laki dari ayahnya. Hukum ini bertujuan untuk keadilan dalam masyarakat karena dalam masyarakat, jika keluarga tidak memiliki anak laki-laki, maka kerabat merendahkan keluarga dengan menghilangkan nama keturunan dalam budaya.

- Teks alkitab dapat melindungi anak perempuan yang haknya sering diambil alih oleh laki-laki, demikian pula dengan hukum waris dalam kitab suci yang menyatakan bahwa anak perempuan dapat memperoleh warisan jika tidak memiliki saudara laki-laki. Dengan demikian anak perempuan menerima keadilan berdasarkan Alkitab.

Berdasarkan data di atas, dapat disimpulkan bahwa ada pihak yang menerima jika anak perempuan mendapat warisan dalam keluarga, dan ada juga yang tidak setuju jika diberikan kepada anak perempuan sebagai, karena hal ini berdasarkan budaya masyarakat Nias.

Bilangan 27:1-11 yakini 'hak waris bagi anak-anak perempuan' yakni berbicara tentang pusaka bagi anak perempuan yakni dari (Yosua 17:6) dan Keluaran 32:1. Pada pasal dan kitab ini, juga menegaskan bagaimana hak warisan dapat diwarisi berdasarkan situasi setiap hukum masing-masing.

Kisah Bilangan 27:1-11 tentang hak waris bagi anak perempuan berkaitan dengan pasal sebelumnya dan pasal berikutnya. Dapat dilihat pada pasal 26, peristiwa sensus kedua yang diadakan untuk bangsa Israel, yaitu generasi pengembara. Di sana, perhitungan dibuat untuk bani Israel dan keturunannya dan dalam menentukan hukum yang harus dijalankan oleh orang Israel sebagai persiapan untuk memasuki tanah Kanaan. Pasal 27:1-11 yang merupakan lanjutan dari kisah sebelumnya, berisi tentang hukum waris bagi anak perempuan Zelafehad yang tidak berjenis kelamin laki-laki tetapi hanya memiliki keturunan perempuan. Kemudian hubungannya dengan pasal setelah pasal 27:1-11 yaitu pasal 36 menjelaskan tentang pemberian hak waris kepada anak perempuan. Ketika wanita menikah, dia harus menikah dengan suku ayahnya. Karena tanah pusaka bukan untuk dipindahkan melainkan untuk didiami di suku tempat asal suku ayah.

Menurut Blomendaal, teks Bilangan 27:1-11 berasal dari sumber $\mathrm{P}$, yaitu dari para imam yang diperkirakan pada tahun 550-500 SM.12 Sumber $\mathrm{P}$ berasal dari para imam pasca pembuangan. Para imam menuliskan $\mathrm{P}$ ini dengan alasan sebelum pembuangan ke Babilon memberi kemungkinan bagi para imam untuk memelihara tradisi-tradisi lisan; namun, dengan pembuangan Babilonia dan penghancuran Bait Suci di Yerusalem, situasinya berubah, karena mengapa? Masalah tanpa kuil di Babel, ditambah dengan bahasa sinkretisme dalam kehidupan keagamaan dan bangsa, semakin mengancam di antara orang-orang kafir, mendorong para imam untuk menuliskan semua tradisi yang ada dan mengumpulkannya agar tidak hilang. Sehingga sumber $\mathrm{P}$ muncul pada tahun 550-500 SM untuk mengingatkan bangsa Israel bahwa mereka adalah umat Allah yang kudus.

Situasi sebelum Teks 27:1-11 muncul ketika bangsa Israel bersiap memasuki tanah Kanaan, tanah yang dijanjikan kepada keturunan Israel. Dalam pasal 26, ada perhitungan dua tentara Israel karena, dalam pasal 25, generasi pertama telah berakhir dengan penghakiman Tuhan atas tindakan perzinahan dan penyembahan Baal, sehingga Tuhan berbicara kepada Musa dan imam Eleazer untuk menyampaikan pesan Tuhan. kepada orang Israel selama berada di dataran Moab. Dengan menghitung jumlah lakilaki yang siap berperang untuk tanah Kanaan, maka mulailah menghitung jumlah yang memiliki keturunan laki-laki dan dapat berperang.

Kemudian setelah dicatat jumlah keturunannya, adapun Zelafehad yang tidak mempunyai anak laki-laki dan hanya mempunyai anak perempuan, sedangkan yang dicatat hanya mereka yang mempunyai keturunan laki-laki, maka dalam ayat 52, Tuhan berfirman kepada Musa: kepada suku-suku negeri itu harus dibagi itu menjadi warisan sesuai dengan nama-nama yang tercatat. Dari catatan nama keturunan Bani Israil, keturunan Zelaphehad tidak tercatat karena hanya memiliki keturunan perempuan. Maka muncul

12 J. Blommendaal, Pengantar Kepada Perjanjian Lama, 15th ed. (Jakarta: BPK Gunung Mulia, 2008). 
teks 27:1-11, yaitu anak-anak Zelafehad datang kepada Musa dan imam Eleazer, untuk menanyakan mengapa milik pusaka ayah mereka tidak diberikan atas nama anak-anak perempuan Zelafehad.

Teks Bilangan 27:1-11 secara tertulis memiliki tujuan, yaitu untuk memberikan pemahaman baik bagi bangsa Israel maupun bagi gereja saat ini. Tradisi atau adat istiadat bangsa Israel yang mengutamakan laki-laki, kini melalui teks ini diketahui bahwa setiap budaya tidak sejalan dengan apa yang tertulis dalam Injil. Tradisi bani Israel yang hanya mengutamakan kedudukan laki-laki, namun melalui teks ini, ada pengetahuan baru bahwa Allah memberikan kesempatan, yaitu bahwa anak perempuan berhak mewarisi harta dengan tujuan untuk menciptakan keadilan baik di antara orang Israel dan juga di antara orang Kristen saat ini.

Dalam perikop ini "hak waris bagi anak perempuan" dimulai dengan kisah ketika generasi kedua Israel telah melewati tanah Moab ke tanah Kanaan, kemudian TUHAN berfirman kepada Musa dan kepada Eleazer, anak imam Harun: 'hitunglah jumlah segenap umat Israel yang berumur genap duapuluh tahun keatas menurut suku mereka, semua orang yang sanggup berperang diantara orang Israel (Bilangan 26:1). Pada pasal 26 dengan memulai perhitungan bilangan dengan mencatat nama-nama orang yang mempunyai keturunan, karena berdasarkan pencatatan nama, tanah akan diberikan kepada Bani Israil. Kemudian mempersiapkan segala peraturan dan ketetapan hukum bagi Bani Israil, termasuk bagian hukum tentang "hak waris bagi anak perempuan" seperti yang Tuhan katakan dalam 27:11b "Inilah hukum bagi orang Israel, seperti yang diperintahkan TUHAN kepada Musa."

Dalam pemberian hak waris kepada putri Zelafehad, ditentukan sebelum memasuki tanah Kanaan. Saat mengembara di gurun, Zelafehad meninggal. Berdasarkan Bilangan 27:3 bahwa Zelafehad mati bukan karena pemberontakannya tetapi karena dosanya. Kemudian setelah Zelafehad meninggal, kaumnya yaitu suku Manasye, ingin membagikan harta pusaka dan tidak memberikannya kepada keturunan Zelafehad karena mereka tidak memiliki anak laki-laki melainkan hanya anak perempuan. Dengan menyebarkan warisan kepada suku Manasye, putri-putri Zelafehad bertanya kepada Musa bagaimana warisan atas nama ayah mereka dapat diberikan kepada putri-putri Zelafehad. Jadi putri Zelafehad muncul di hadapan Musa dan di hadapan Eleazer, sang imam.

Zelafehad berasal dari suku Manasye keturunan Yusuf (Bil. 26:28) beserta sukunya yang mengembara di padang gurun ke tanah Kanaan. Zelophehad ini tidak mencapai tanah Kanaan, dia meninggal saat mengembara di padang gurun, sehingga warisannya dibagikan di antara suku-sukunya. Melihat keadaan tersebut, putri-putri Zelafehad memohon kepada Musa dan imam Eleazer bagaimana agar pusaka (tanah warisan) atas nama ayah Zelafehad dapat diberikan kepada putriputrinya.

Dalam pasal 26:1 ketika Tuhan menyuruh Musa untuk memerintahkan para imam untuk menghitung jumlah dan mencatat nama-nama keturunan yang memiliki keturunan dan bisa berperang dalam persiapan untuk tanah Kanaan. Dalam pencatatan nama-nama ini, semua kaum dicatat mulai dari kaum Ruben sampai orang Lewi (Bil. 26:5-65). Dalam pasal 26:33, dikatakan bahwa Zelafehad tidak memiliki keturunan laki-laki dan hanya memiliki keturunan perempuan. Dengan demikian, namanya tidak tercatat karena yang tertulis dalam sensus adalah seperti yang diperintahkan oleh Musa, yaitu anak-anak yang bisa berperang. Zelafehad tidak memiliki anak laki-laki. Oleh karena itu, namanya tidak terdaftar di antara kaumnya, dan dia juga kehilangan warisan. Kisah ini menggambarkan diskriminasi terhadap perempuan di zaman Musa. Menurut hukum Ibrani, itu bukan untuk memberikan warisan bagi anak perempuan, dan itu telah menjadi tradisi Israel pada waktu itu.

Dalam pasal 27:4, ketika anak perempuan Zelafehad bertanya dan menyampaikan segala perkawa kepada imam Eleazer dan Musa, yakni "mengapa nama ayah kami harus hapus ditengahtengah kaumnya, oleh karena ia tidak mempunyai anak laki-laki? Berilah kami tanah milik di antara saudara-saudara ayah kami." Anak-anak Zelafehad bertanya tentang hak yang harus mereka miliki, meskipun ayah mereka telah meninggal dan tidak memiliki anak laki-laki, tetapi mereka masih memiliki keturunan perempuan. Rupanya, dalam teks ini, anak-anak Zelafehad 
menunjukkan keberanian anak dalam memperjuangkan nama ayah mereka yang telah dihapuskan di antara kaumnya. Bagi bangsa Israel, nama merupakan identitas yang sangat berpengaruh dalam pembagian harta warisan, karena dengan tercatatnya nama ayah maka keturunan ayah tidak kewalahan untuk mendapatkan harta warisan. Ketika nama itu didaftarkan, maka identitas dalam pemilikan harta pusaka itu tidak hilang dari keturunannya. Demikian pula Allah mendengar kasus anak perempuan Zelafehad, yang disebutkan dalam ayat ke-8, yaitu bahwa anak perempuan mendapat warisan dalam keluarga, dan ketika mereka tidak memiliki anak, anak laki-laki dan perempuan akan dipindahkan ke saudara laki-laki ayah. Maka Allah menetapkan hukum waris bagi anak perempuan karena hukum dalam hal ini menunjukkan tempat dan martabat serta kehormatan yang diberikan kepada perempuan di Israel.

נִחדְלָה 'Nahala' dalam bahasa Inggris inheritance yang artinya warisan, harta atau

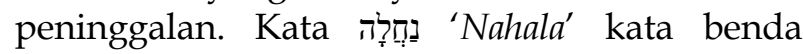
feminim tunggal dengan kata dasar 'nahal' yakni mendapat milik pusaka [eksegese dari kata pusaka terjemahan dari bahasa Ibrani].

Dari istilah di atas, dengan menggunakan kata dasar נחל 'nahal' yakni mendapat milik pusaka. Kata pusaka menunjukan feminim bentuk tunggal yang mengarah kepada perempuan yakni berhak untuk mendapatkan harta warisan. Pusaka dalam istilah teks ini berupa tanah milik dari ayah atau warisan, yang hendak dialihkan atau diberikan kepada anak perempuan karena tidak memiliki keturunan laki-laki.

Bangsa Israel adalah bangsa yang menganut budaya patriarkat. Bagi orang Israel, nilai laki-laki lebih tinggi daripada perempuan. Hal ini terlihat dari setiap kisah dalam Alkitab, yaitu bangsa Israel yang melakukan perhitungan silsilah; hanya laki-laki yang dihitung. Dalam kitab Bilangan, ada dua sensus untuk orang Israel, dan hanya laki-laki yang dimasukkan dalam hitungan. Budaya patriarkat adalah sistem yang kuat untuk mempengaruhi masyarakat Israel. Apapun cara yang berhubungan dengan masyarakat atau kehidupan orang Israel, laki-laki yang berhak dianggap sebagai satu-satunya keturunan dan mereka yang mewarisi warisan dari ayah mereka.

Budaya patriarkat sangat berpengaruh dalam mengangkat harkat dan martabat anak laki-laki dibandingkan dengan anak perempuan. Namun, jika secara alkitabiah dinyatakan dalam (Kej. 1:26-27; 2:18) "Manusia segambar dan serupa dengan Allah" kemudian "tidak baik kalau manusia itu hanya seorang diri saja, maka harus ada penolong baginya." Ayat ini menunjukkan bahwa di dalam Alkitab, baik pria maupun wanita sama di mata Tuhan, tidak ada yang lebih tinggi, dan tidak ada yang lebih rendah, semuanya memiliki kesetaraan di hadapan Tuhan dan dapat menjadi penolong bagi orang lain.

Dalam Bilangan 27:1-11, 'keberanian putriputri Zelafehad, yang mencoba meminta keadilan sejati melalui warisan. Hal ini menggambarkan bahwa dalam budaya atau adat istiadat, harkat dan martabat laki-laki sangat ditinggikan, tetapi secara teologis perempuan berhak mewarisi harta dalam keluarga. Pusaka dalam bahasa Ibrani 'nahala' kata benda feminim tunggal dengan kata dasar 'nahal' merupakan mendapatkan milik pusaka."

Dalam ayat $11 b$ TUHAN telah menetapkan "hukum" yakni dari ayat 8-11a:

- Apabila seorang mati dengan tidak memiliki anak laki-laki, maka haruslah kamu memindahkan hak atas milik pusakanya kepada anaknya yang perempuan.

- Apabila tidak mempunyai anak perempuan, maka haruslah kamu memberikan milik pusakanya kepada saudara-saudaranya yang laki-laki.

- Dan apabila ia tidak mempunyai saudarasaudara lelaki, maka haruslah kamu memberikan milik pusakanya itu kepada kepada kerabatnya yang terdekat dari antara kaumnya, supaya dimilikinya.

Ini adalah ketetapan hukum yang diucapkan oleh Tuhan kepada Musa dan kemudian disampaikan kepada orang Israel [Bilangan 27:1-11]. Tujuan hukum ini bagi bangsa Israel adalah untuk menciptakan ketertiban bagi rakyat dan keadilan yang harus dilakukan oleh bangsa Israel. Kata Hukum dalam bahasa Ibrani adalah 'keadilan', sehingga selain menciptakan ketertiban di tengah 
masyarakat, juga menciptakan keadilan di tengah masyarakat yang berbudaya Kristen.

Melalui teks Bilangan 27:1-11, Allah menetapkan hukum warisan bagi bangsa Israel; secara psikologis, dibutuhkan keadilan bagi seluruh umat manusia demi keberadaan Tuhan. Berdasarkan peristiwa dan situasi yaitu ketika anak-anak Zelafehad menuntut hak untuk mendapatkan warisan yang dimiliki oleh ayah Zelafehad. Makna teologisnya adalah Allah memberikan hak kepada anak perempuan Zelafehad untuk mendapatkan warisan - untuk menciptakan keadilan antara anak laki-laki dan anak perempuan. Dengan demikian, anak perempuan tidak merasa bahwa laki-laki mengambil alih hak mereka. Dalam ayat $11 \mathrm{~b}$ Allah menetapkan hukum bagi orang Israel tentang kepemilikan anak perempuan. Hukum adalah aturan, dan masyarakat harus menjalankan aturan itu sebagai orang Kristen.

Anak perempuan Zelafehad meminta warisan ayah mereka, dan Allah memberikan warisan. Demkian, anak perempuan Sifalago Gomo melakukan hal yang sama, yaitu meminta agar harta warisan yang dimiliki ayahnya dapat diberikan juga kepada mereka. Tetap saja, akibatnya, permintaannya tidak dikabulkan, meskipun keluarga itu tidak memiliki saudara laki-laki. Dalam hal ini, warisan dialihkan kepada anak laki-laki dari saudara laki-laki ayah anak perempuan.

\section{KESIMPULAN}

Anak laki-laki mendapatkan warisan berdasarkan tradisi budaya. Dalam aturan atau adat istiadat masyarakat Nias, anak laki-laki adalah ahli waris atas harta benda yang dimiliki oleh keluarga, baik berupa tanah maupun yang berhak atas rumah ketika ayahnya meninggal. Hal ini ditentukan oleh latar belakang masyarakat Nias, yaitu bahwa anak laki-laki memiliki kemampuan atau kelebihan yang tidak dimiliki anak perempuan dan anak laki-laki tinggal di samping orang tuanya. Sebaliknya, anak perempuan tidak selalu tinggal di samping orang tua mereka karena mereka menikah serta ikut suami.

Berdasarkan kisah anak-anak Zelafehad dalam Bilangan 27:1-11, karena keluarga hanya mempunyai anak perempuan dan tidak ada anak laki-laki, maka harta pusaka yang dimiliki orang dapat diberikan kepada anak perempuan karena keluarga tersebut tidak mempunyai saudara laki-laki.

Temuan penelitian menunjukkan bahwa ada keluarga yang juga memberikan sebagian hak waris kepada anak perempuannya karena menurut orang tua, baik anak laki-laki maupun perempuan memiliki hak atas harta yang dimiliki oleh orang. Anak laki-laki dan perempuan adalah anak yang mereka lahirkan; meskipun anak perempuan menikah dan ikut suami, mereka adalah anak. Baik anak laki-laki maupun perempuan memiliki derajat yang sama di mata Tuhan karena mereka diciptakan menurut gambar dan rupa Tuhan dan tentunya memiliki hak yang sama, seperti yang diwahyukan dalam kitab Kejadian. 1:26, manusia diciptakan menurut gambar dan rupa Allah. ${ }^{13}$

Kisah anak-anak Zelafehad menjadi pedoman bagi kehidupan komunitas Kristen di Sifalago Gomo, karena Tuhan yang Maha Bijaksana memberikan kesempatan kepada anak perempuan untuk menerima warisan serta seharusnya pemimpin adat dan keluarga, dapat menjadikan kisah anak perempuan Zelafehad sebagai pedoman dalam memperlakukan anak perempuan secara adil, baik dalam masyarakat, gereja dan terutama dalam keluarga.

\section{REFERENSI}

Bernard, H. Russell. Research Methods in Anthropology: Qualitative and Quantitative Approaches. 6th ed. Maryland: Rowman \& Littlefield, 2017.

Blommendaal, J. Pengantar Kepada Perjanjian Lama. 15th ed. Jakarta: BPK Gunung Mulia, 2008.

Dachi, Otoriteit, and Vinna Isya Merti Manao. "Pelayanan Dan Kepemimpinan Pendeta Perempuan BNKP." SUNDERMANN: Jurnal Ilmiah Teologi, Pendidikan, Sains, Humaniora dan Kebudayaan 14, no. 1 (October 6, 2021): 29-38.

https://jurnal.sttsundermann.ac.id/index.ph $\mathrm{p} /$ sundermann/article/view/66.

13 Juliman Harefa, "Makna Allah Pencipta Manusia Dan Problematika Arti Kata 'Kita' Di Dalam Kejadian 1:26-27," EPIGRAPHE: Jurnal Teologi dan Pelayanan Kristiani 3, no. 2 (December 18, 2019): 107, http://www.stttorsina.ac.id/jurnal/index.php/epigrap he/article/view/134. 
Gulo, W., ed. "Injil Dan Budaya Nias." In Seminar Lokakarya Perjumpaan Injil Dan Budaya Nias. Gunungsitoli: Panitia Semiloka, 2004.

Gulo, Yurulina. "Ketidakadilan Budaya Patriarkhi Terhadap Perempuan Di Nias." JUPIIS: Jurnal Pendidikan Ilmu-ilmu Sosial 11, no. 1 (June 18, 2019): https://jurnal.unimed.ac.id/2012/index.php /jupiis/article/view/12305.

Harefa, Juliman. "Makna Allah Pencipta Manusia Dan Problematika Arti Kata 'Kita' Di Dalam Kejadian 1:26-27." EPIGRAPHE: Jurnal Teologi dan Pelayanan Kristiani 3, no. 2 (December 18, 2019):

107. http://www.stttorsina.ac.id/jurnal/index.ph $\mathrm{p} /$ epigraphe/article/view/134.

Laia, Fanotona. "Kedudukan Anak Perempuan Dalam Hukum Waris Adat Pada Masyakakat Nias." Universitas Sumatera Utara, 2005. http://repositori.usu.ac.id/handle/12345678 9/33440.

Laoli, Memori Perdamaian. "Pelaksanaan Pembagian Warisan Pada Masyarakat Adat Nias (Studi Pada Masyarakat Adat Nias Di Kabupaten Nias Selatan)." Premise Law Jurnal. Universitas Sumatera Utara, 2016.

Poespasari, Ellyne Dwi. Pemahaman Seputar Hukum Waris Adat Di Indonesia. 1st ed. Jakarta: Prenadamedia Group, 2018.

Smit, Brigitte, and Anthony J. Onwuegbuzie. "Observations in Qualitative Inquiry: When What You See Is Not What You See." International Journal of Qualitative Methods 17, no. 1 (December 2018).

Soekanto, Soerjono. Hukum Adat Indonesia. Jakarta: Rajawali Pers, 2008.

Telaumbanua, Tuhoni. "Dunia Orang Mati Menurut Kepercayaan Masyarakat Nias." SUNDERMANN: Jurnal Ilmiah Teologi, Pendidikan, Sains, Humaniora dan Kebudayaan 14, no. 1 (June 26, 2021): 1-17. https://jurnal.sttsundermann.ac.id/index.ph $\mathrm{p} /$ sundermann/article/view/49. 